\title{
Using Retrospective Surveys to Assess the Impact of Participating in an Afterschool Maker Learning Program on Youth
}

\section{Dr. Foad Hamidi, University of Maryland, Baltimore County}

Dr. Foad Hamidi is an Assistant Professor at the University of Maryland, Baltimore County (UMBC). His research interests include Human-Computer Interaction, Participatory Design and Assistive Technology.

\section{Ms. Adena Moulton, Digital Harbor Foundation}

Adena Moulton manages Digital Harbor Foundation's research initiatives, program evaluation processes, grant development, and fundraising initiatives. Adena formerly worked as a Researcher for the WomanStats Project studying violence against women, the Woodrow Wilson International Center for Scholars studying the 2011 Arab Uprisings, and Brigham Young University's Political Science Department studying marriage and family practices of the Middle East. She graduated with a Bachelor's Degree in Middle Eastern Studies and Arabic from Brigham Young University where she received the Middle East Studies/Arabic Student Research Award in April 2017.

\section{Shawn Grimes, Unaffiliated}

Shawn Grimes has nearly 20 years of experience as a technologist in a variety of fields including mobile app development, cyber security, and software engineering. Through his passion for working with and serving youth, he served as the Director of Technology at the Digital Harbor Foundation where their work focused on teaching technology and maker skills to youth.

\section{Stephanie Grimes,}

Steph Grimes served as the Director of Programs \& Education at Digital Harbor Foundation in Baltimore, MD from 2012-2019, where she lead a team in managing and creating out-of-school programs for youth, and professional development workshops for educators, focused on maker and technology education.

\section{Andrew Coy, Digital Harbor Foundation}

Andrew is the founder and current Executive Director of the Digital Harbor Foundation. He also served as a senior advisor in the Office of Science and Technology Policy during the Obama administration and currently advises national technology education nonprofits including the Computer Science for All and Nation of Makers. Andrew was also the lead author on the Maryland Access Task Force report to Maryland's Governor Larry Hogan. His work has been recognized by Baltimore Business Journal, The Daily Record, Forbes Magazine, Baltimore Sun, Education Week, and K12 Magazine. 


\title{
Using Retrospective Surveys to Assess the Impact of Participating in an Afterschool Maker Learning Program on Youth (RTP)
}

\begin{abstract}
As the number of afterschool technology-rich maker learning programs for youth increases, it is important to investigate effective assessment tools that can be used to assess program impact at scale. We studied results from a series of surveys using two deployment modes with 94 youth who participated in programs at an afterschool maker learning center. We found that retrospective surveys that ask youth to reflect on shifts in their attitudes after completing a program are more effective than the same surveys deployed twice, pre- and post- a program. These results confirm input from youth interviews in which they expressed dislike of repeating the same surveys before and after a program and difficulty with answering self-assessment questions without a point of reference.
\end{abstract}

\section{Introduction}

Afterschool maker programs provide opportunities for engaging youth in hands-on projects that require creative problem solving, teamwork and the acquiring and application of technical skills [1][2][3]. These programs can introduce participants to engineering concepts and skills before college [1][4]. As more organizations offer maker programs to hundreds, if not thousands, of youth, it becomes increasingly important to identify valid and scalable evaluation methods by conducting assessments that capture the impact of participation on youth.

Previous research has proposed different qualitative and quantitative approaches to assessing the learning outcomes of maker programs. While most existing research has focused on developing qualitative tools [5], there is also a need for developing and adopting context-aware quantitative assessment tools that can be deployed broadly in maker programs [1][6][7]. Previous research on assessment tools for youth in maker programs showed that youth had negative attitudes towards surveys in this context and generally preferred methods that required creativity and selfexpression [6][7]. Building on these results, in this project we focused on comparing different survey deployment modes in maker settings: (1) a pre-post mode, where we deployed surveys before and after a program, and (2) a retrospective mode, where we deployed a single survey at the end of a program and asked participants to reflect on their abilities and attitudes before and after the program. In this evaluation paper, we report the results of investigating the impact of an afterschool maker program on 94 youth. Three times over 12 months, we collected data using a series of survey tools including two Upper Elementary School and Middle/High School Student Attitudes toward STEM (S-STEM) Surveys (Technology and Engineering and $21^{\text {st }}$ Century Skills) [8] and the Alternative Uses Test (AUT) [9][10]. Additionally, we conducted interviews with representative youth about their perceptions and attitudes towards the surveys.

While the AUT results showed a positive change in the youth, initial results from pre-post STEM-S evaluations showed insignificant and sometimes negative shifts in youth's interests towards Technology and Engineering, and $21^{\text {st }}$ Century Skills. Interviews showed that youth struggled to accurately assess changes in themselves due to the time lapse between pre-post program surveys. Additionally, they did not see the value of completing the surveys. We subsequently changed the format of the surveys to a retrospective form to help youth better reflect on their attitudes and skills. The results of the retrospective surveys showed significant 
positive shits in youth interest in technology and engineering, and $21^{\text {st }}$ century skills. We present detailed results and recommendations on how to apply these surveys in other, similar programs.

\section{Literature Review}

Interest in using maker and DIY approaches to engage youth and adults in Science, Technology, Engineering and Mathematics (STEM) topics has received considerable interest in the past few decades [1]-[5]. Previous research has shown that maker programs can support self-directed learning, collaboration with others on group projects and the acceptance of failure and support diverse participants to learn technical, as well as, interpersonal skills [5]. Studies have further shown that participating in hands-on making activities can positively impact self-efficacy [1][11], technological awareness and confidence [13], and general and declarative knowledge of technical systems [5][14]. Additionally, previous research has shown that maker activities can be presented in different configurations and formats in informal settings, including after-school programs, workshops, and summer camps, attracting a wide range of participants [1]-[7].

A recent systematic literature review has shown that the number of empirical studies of learning outcomes of maker workshops and programs has significantly increased in the last few years [5]. The review further showed that most of the empirical studies of the outcomes of maker activities (57\%) employed qualitative methods [5]. The qualitative assessments included open portfolios [12] and peer- and self-assessments [11].

While using these qualitative measures have been effective in maker settings, as the scale of maker programs increase and assessments have to be conducted for larger numbers of participants, it is important to study the possibilities and challenges of quantitative measures that may complement existing tools. According to the systematic literature review discussed previously, the majority of the quantitative measures used in the studies of maker programs focused on assessing knowledge of school concepts and the impact of participating in maker programs on academic school performance [5]. There was a lack of empirical data measuring the interest and creativity of participating youth. Previous research has also identified challenges with deploying quantitative assessments in maker settings. For example, Hamidi et al. observed that youth participating in afterschool maker programs had negative attitudes towards quantitative surveys and self-assessments due to their similarity to school assessments and their administration interrupting hands-on maker activities [6][7]. These attitudes could lead to a lack of motivation in participation and decreased survey completion rates.

In recent years, researchers have explored the possibility of incorporating maker activities in formal school classrooms [1]. In a year-long study with 121 middle-school students (ages 8-11) who participated in weekly maker activities incorporated into school days, Chu et al., found significant impacts on students' science self-efficacy and identity, as well as, making selfefficacy and interest. The researchers developed a series of survey instruments for the project that they deployed in a pretest-posttest mode to measure youth's interest, self-efficacy and selfidentity with respect to making and science [1].

In addition to the type of assessment and the specific tools used, the mode of deployment can also impact results. The majority of previous studies in this context have utilized a pretestposttest mode where assessment tools are deployed before and after the completion of a program, 
workshop and activity. A comparison of the results can then show shifts in outcomes. An alternative to the pre-post deployment mode is the retrospective mode, where participants are asked to reflect on an aspect of their interest, learning or perspective [17]. Previous research has shown that this mode is effective at improving completion modes, reducing the amount of time needed for assessment, and providing a better frame of reference for comparison to participants [18][19].

To date, the majority of previous research on assessing maker outcomes for youth have focused on using qualitative tools. Given the increasing number of youth and adults in maker programs, more research on potentially effective methods and modes for deploying them in this setting is needed. In this project, we used empirical data to study different quantitative assessment tools and modes of deployment to determine suitable configurations for use in maker contexts.

\section{Research Setting}

This project took place at a non-profit organization, the Digital Harbor Foundation (DHF), that provides afterschool informal maker learning and training programs to youth (grades 1-12). DHF is located a large American city and serves youth from a wide range of socio-economic backgrounds. A key goal of DHF is to use technology to provide engaging and hands-on learning and creative experiences for inner-city youth. Thus, the organization offers a range of STEMbased courses, including programs that focus on digital fabrication and computer science, on a pay-what-you-can basis.

Most DHF programs take the form of 7 or 14-week courses. Classes meet for two-hour sessions twice a week and cover a variety of topics and activities. These programs operate on a workshop structure that provides significantly more flexibility than a traditional classroom setting. DHF's 14-week introductory course, Maker Foundations, introduces incoming middle and high school youth to key maker concepts and practices including 3D printing, circuitry, graphic design, game development, and coding. Upon completion, youth become DHF Members and can register for a variety of more advanced, focused courses. DHF programs are offered using a Fall, Spring and Summer trimester model. While the Fall and Spring sessions are very similar, Summer programs are often much shorter and differ in content and format.

DHF prioritizes self-directed learning, with programs designed to encourage participants to explore online and offline resources independently and continue work beyond face-to-face time. Programs also emphasize interdisciplinary projects that combine art, science, and technology. Once program staff present technical material, youth work on self-directed projects that they come up with themselves. These projects are supported by DHF staff who answer questions and help youth find resources to address problems. DHF also highly values teamwork, and small teams of youth often complete and present projects. Figure 1 shows a typical DHF course setting. 


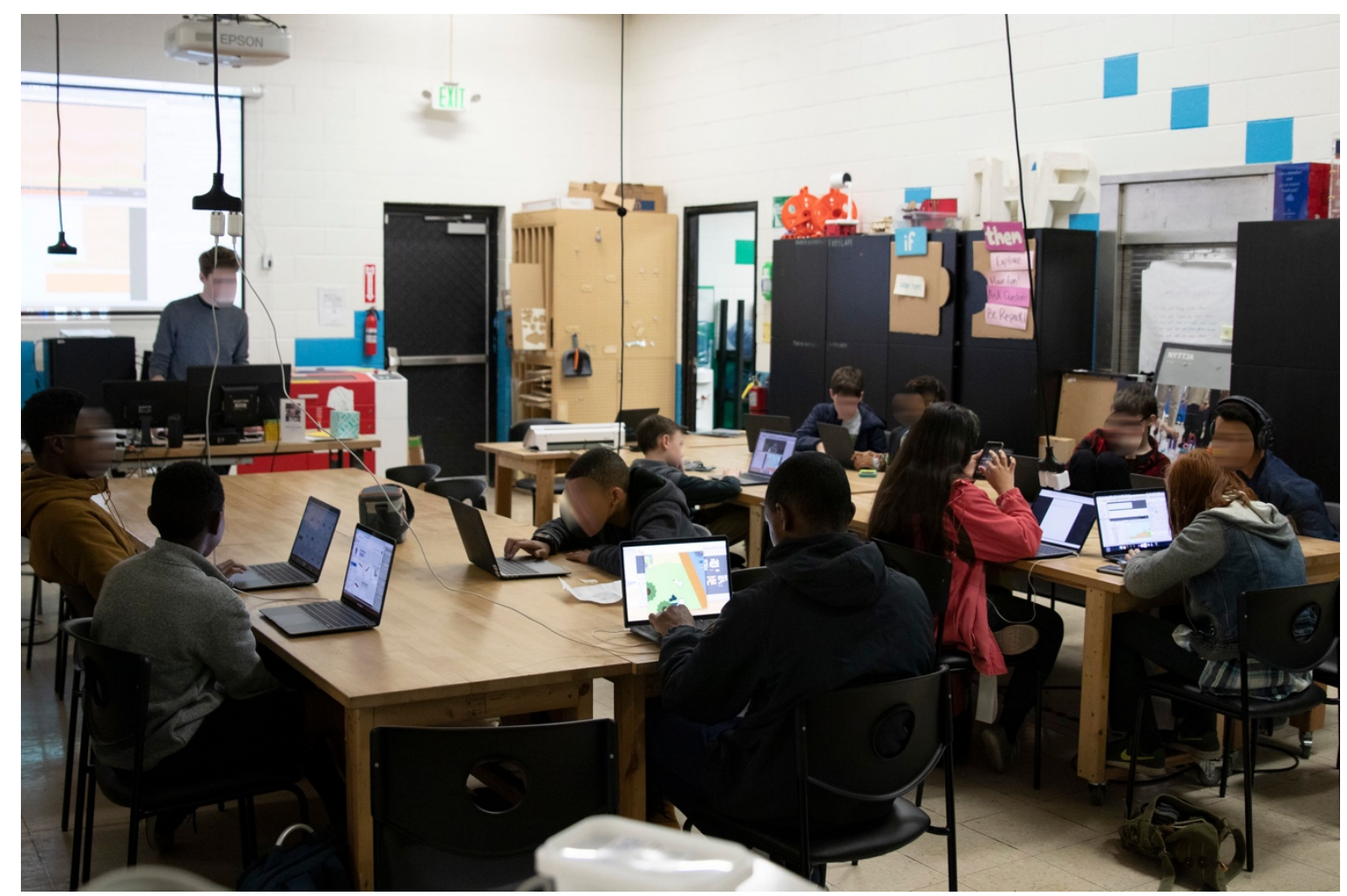

Figure 1: Typical setting for DHF's courses: Classes take place in a large, open-plan space where youth work on self-directed projects and learn about design thinking, digital fabrication and computer science.

Key components of many DHF courses, including Maker Foundations, are digital fabrication, circuitry, coding and web development. The fabrication modules consist of 3D modeling and printing, as well as, laser cutting exercises and the use of a variety of materials including metal and wood. The fabricated objects are often combined with interactive electronic components, such as Makey Makey's and Arduinos. A typical youth project might include the design and 3D printing of an interactive customized controller for a game developed by the youth on an entrylevel coding platform, such as Scratch.

DHF has delivered programs to more than 5000 youth since 2013. In the past few years, the organization has experienced increased demand for the growth of their youth intake numbers and also for helping program staff in other locations and cities develop and implement similar programs. This surge in interest has motivated the organization to investigate the implementation of effective, efficient, and sustainable ways to assess program outcomes at scale.

\section{Methods and Analysis}

\subsection{Participants}

The data presented in this paper was collected from four groups of youth participants (total $n=$ 94) who were completing programs at DHF. The data was collected during Fall'18 and Spring' 19 semesters. At each semester, a group of incoming youth and member youth participated in the data collection. The incoming youth who completed the surveys were between 
11-15 years old (grades 6-10) and the experienced youth members were between 11-18 years old (grades 6-12). Table 1 shows an overview of participants and data collection procedures.

During the Fall' 18 semester, we deployed AUT and STEM-S Surveys for the incoming youth $(n=20)$ and STEM-S surveys for the member youth $(n=16)$. We deployed all surveys using the pre-post mode. Following the initial data analysis phase, we conducted interviews with 2 youth from the member group. In Spring'19, we deployed STEM-S surveys for both incoming $(\mathrm{n}=19)$ and member youth $(n=39)$ using the retrospective mode.

\begin{tabular}{|c|c|c|c|}
\hline Participants & Number & Age & Procedures \\
\hline Incoming Youth -Fall'18 & $20^{*}$ & $11-15$ & $\begin{array}{c}\text { STEM-S Surveys (Pre-Post), } \\
\text { AUT (Pre-Post) }\end{array}$ \\
\hline Member Youth - Fall'18 & 16 & $11-18$ & STEM-S Surveys (Pre-Post) \\
\hline Member Youth - Fall'18 & 2 & $11-18$ & Interviews \\
\hline Incoming Youth - Spring'19 & 19 & $11-15$ & $\begin{array}{c}\text { STEM-S Surveys } \\
\text { (Retrospective) }\end{array}$ \\
\hline Member Youth - Spring'19 & 39 & $11-18$ & $\begin{array}{c}\text { STEM-S Surveys } \\
\text { (Retrospective) }\end{array}$ \\
\hline
\end{tabular}

Table 1. Participants and Data Collection Procedures. *One of the Incoming Youth-Fall'18 group did not complete AUT.

\subsection{Procedures}

\subsubsection{Surveys}

We analyzed results from two quantitative assessment tools used at DHF, the Upper Elementary School and Middle/High School Student Attitudes toward STEM (S-STEM) Surveys, and Alternative Uses Test (AUT). The STEM-S surveys measure youth's interests towards a set of 4 validated constructors each corresponding to Science, Technology and Engineering, Math, and $21^{\text {st }}$ Century Skills areas [8]. $21^{\text {st }}$ century skills refer to critical-thinking, communication and collaboration. The surveys also include a section on interests towards STEM careers. Interest in each topic is measured using a series of 8 to 11 self-reported Likert style items (Table 2). Each item has to be rated on 5 levels ranging from "Strongly Disagree" to "Strongly Agree". The STEM Careers survey consists of 12 items that are rated across 4 levels of interest, ranging from "Not at All Interested" to "Very Interested".

After reviewing the contents of each survey and taking into account findings from previous research that shows youth prefer short assessments [6][7], we decided to only deploy surveys relating to two topics relevant to DHF's learning objectives. These included the Technology and Engineering ( 9 items) and $21^{\text {st }}$ Century Skills (11 items). The original paper survey was converted to a digital online survey that was completed by youth in DHF.

\section{Technology and Engineering}

1. I like to imagine creating new products.

2. If I learn engineering, then I can improve things that people use every day.

3. I am good at building and fixing things.

4. I believe I can be successful in a career in engineering. 


\section{$21^{\text {st }}$ Century Skills}

1. I am confident I can lead others to accomplish a goal.

2. I am confident I can encourage others to do their best.

3. I am confident I can produce high quality work.

4. I am confident I can respect the differences of my peers.

Table 2. Example items from the two surveys of S-STEM Survey [8], Technology and Engineering 9 and $21^{\text {st }}$ Century Skills, 11 used in the pre-post mode

We collected the STEM-S survey twice from youth participating in two courses, an introductory course and an DHF members course. The first time the measure was used in a pre-post mode where the same questions were presented to the youth before and after course completion. The second time, we deployed the survey using a retrospective mode where the youth were asked about their interests only once after the completion of the course. However, in this mode youth were asked to answer each question twice, once reflecting their interest before and once after completing the course. Table 3 shows sample questions from the survey subsections and the accompanying text that was used in this mode.

\section{Technology and Engineering}

Please tell us how much you agree with each statement based on your experience in this course. You will select two answers for each item.

The first answer should tell us how much you would have agreed BEFORE THIS COURSE. The second answer should tell us how much you agree now AFTER THIS COURSE.

1a. I like to imagine creating new products - BEFORE this course.

1b. I like to imagine creating new products - AFTER this course.

2a. If I learn engineering, then I can improve things that people use every day- BEFORE this course.

2b. If I learn engineering, then I can improve things that people use every day - AFTER this course.

3a. I am good at building and fixing things - BEFORE this course.

3b. I am good at building and fixing things - AFTER this course.

4a. I believe I can be successful in a career in engineering - BEFORE this course.

4b. I believe I can be successful in a career in engineering - AFTER this course.

\section{$21^{\text {st }}$ Century Skills}

1a. I am confident I can lead others to accomplish a goal - BEFORE this course.

1b. I am confident I can lead others to accomplish a goal - AFTER this course.

2a. I am confident I can encourage others to do their best - BEFORE this course.

2b. I am confident I can encourage others to do their best - AFTER this course.

3a. I am confident I can produce high quality work - BEFORE this course.

3b. I am confident I can produce high quality work - AFTER this course.

4a. I am confident I can respect the differences of my peers - BEFORE this course.

4b. I am confident I can respect the differences of my peers - AFTER this course.

Table 3. Example items from the two surveys of S-STEM Survey [8], Technology and Engineering and $21^{\text {st }}$ Century Skills, used in the retrospective mode 
The Alternative Uses Test (AUT) is a well-established tool for measuring Divergent Thinking, a type of thinking process used in problem solving. Divergent thinking involves identifying and considering multiple related but distinct concepts or solutions [9]. It is viewed as highly correlated with creativity and problem-solving [9]. To take AUT, facilitators present participants with a series of common object names (e.g., pencil, tire, ...) and instruct them to identify as many different but practical uses as possible for each object. A common or primary use is provided for each object and participants are instructed to "list as many as six other uses for which the object or parts of the object could serve." For example, for a newspaper that is commonly used for reading, alternative uses can include, starting a fire, wrapping garbage, swatting flies, etc. Previous research has shown that youth attitudes in maker settings towards AUT are generally more positively than other assessments [6][7]. When conducting AUT, DHF staff followed instructions standardized and distributed by the Mind Garden organization [20]. for deploying the tool and scoring the results. Based on previous deployments of the test, the staff developed an electronic version of AUT that youth could complete on a computer. The test consisted of two identical parts. In each part, youth received 3 prompts and a 4-minute timer While youth completed the activities, an instruction slide with a timer and pictures of the items was projected on an overhead display. Figure 2 shows a screenshot of the instruction slide.

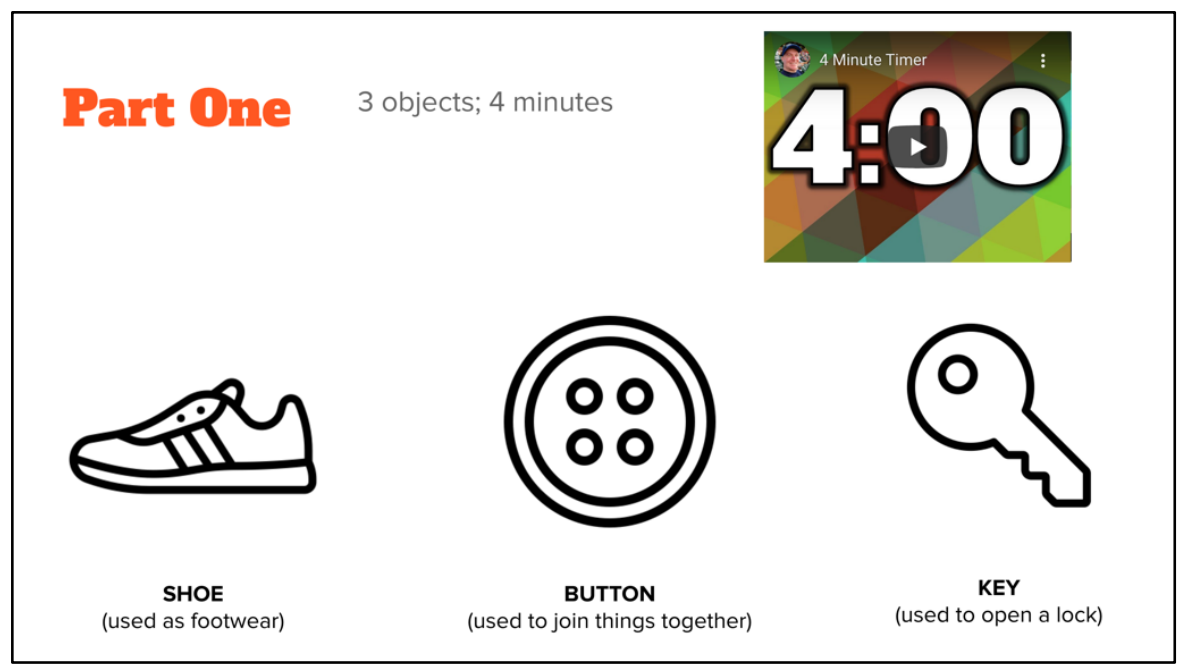

Figure 2: A slide shown to youth while they complete the Alternative Uses Test (AUT) on computers. It includes pictures of three items they need to brainstorm alternative uses for and a timer.

\subsubsection{Interviews with Representative Youth}

We conducted short semi-structured interviews (between 11-17 minutes) with 2 member youth who had participated in the first series of pre-post surveys. In the interviews, we asked youth for their perspectives on the surveys and any difficulties in responding to them. We recorded and analyzed the interviews to identify elements of the survey youth found rewarding or difficult.

\section{Findings}

\subsection{Survey Results}

Results from the STEM-S surveys show a marked difference between pre-post and retrospective modes. Table 4 shows an overview of the survey outcomes. We conducted paired t-tests for all groups to determine significant shifts. For all survey results, we calculated and used the 
interquartile range to find and remove outliers. Using this method, we found and removed one outlier from the Member Youth, Spring'20 group.

The pre-post mode showed statistically insignificant shifts for the Technology and Science Interest of both incoming, $\mathrm{t}(19)=2.07, \mathrm{p}=\mathrm{ns}$, and member youth, $\mathrm{t}(15)=0.34, \mathrm{p}=\mathrm{ns}$. The prepost mode also showed insignificant shifts in $21^{\text {st }}$ Century skills for both incoming, $\mathrm{t}(19)=1.28$, $\mathrm{p}=\mathrm{ns}$, and member youth, $\mathrm{t}(15)=0.74, \mathrm{p}=\mathrm{ns})$. The shifts were negative for the incoming youth and positive for the member youth.

In contrast, the retrospective mode captured statistically significant shifts for both surveys and groups. Paired t-test showed significant positive shifts for the Technology and Science Interest of incoming youth, $\mathrm{t}(18)=3.77, \mathrm{p}<.005$, and member youth, $\mathrm{t}(37)=4.58, \mathrm{p}<.0001)$. There were also significant shifts for the $21^{\text {st }}$ Century skills of both the member youth, $t(37)=3.06, p<.005$, and the incoming youth, $\mathrm{t}(18)=2.35, \mathrm{p}<.05)$, groups. Additionally, the percentage of increased interest as reflected by the retrospective surveys was much higher both for Technology and Engineering survey (43.21\%), and the $21^{\text {st }}$ Century Skills survey (13.96\%). for incoming youth than member youth.

\begin{tabular}{|c|c|c|c|c|}
\hline Survey (Mode) & $\begin{array}{l}\text { Technology and } \\
\text { Engineering } \\
\text { (Pre-Post) }\end{array}$ & $\begin{array}{c}21^{\text {st }} \text { Century } \\
\text { Skills } \\
\text { (Pre-Post) }\end{array}$ & $\begin{array}{l}\text { Technology } \\
\text { and } \\
\text { Engineering } \\
\text { (Retroactive) }\end{array}$ & $\begin{array}{l}21^{\text {st }} \text { Century } \\
\text { Skills } \\
\text { (Retroactive) }\end{array}$ \\
\hline Population & \multicolumn{2}{|c|}{ Incoming Youth - Fall'18 } & \multicolumn{2}{|c|}{ Incoming Youth - Spring'19 } \\
\hline $\begin{array}{l}\% \text { of youth with } \\
\text { increased interest }\end{array}$ & $20 \%$ & $20 \%$ & $78.95 \%$ & $57.89 \%$ \\
\hline $\begin{array}{l}\% \text { of overall increase or } \\
\text { decrease }\end{array}$ & $-8.56 \%$ & $-3.65 \%$ & $81.03 \%$ & $35.43 \%$ \\
\hline Population & \multicolumn{2}{|c|}{ Member Youth - Fall'18 } & \multicolumn{2}{|c|}{ Member Youth - Spring'19 } \\
\hline $\begin{array}{l}\% \text { of youth with } \\
\text { increased interest }\end{array}$ & $41.17 \%$ & $62.5 \%$ & $56.26 \%$ & $57.89 \%$ \\
\hline $\begin{array}{l}\% \text { of overall increase or } \\
\text { decrease }\end{array}$ & $1.38 \%$ & $2.27 \%$ & $37.82 \%$ & $21.47 \%$ \\
\hline
\end{tabular}

Table 4. Overview of STEM-S Survey Results for incoming and member youth.

With respect to AUT, there were considerable gains across pre-post results for the incoming youth $(68.42 \%$ of youth had increases in their score, with an overall increase of $30.43 \%)$. However, a paired t-test did not show a statistically significant difference between the pre and post results, $\mathrm{t}(18)=1.99, \mathrm{p}=\mathrm{ns}$.

\subsection{Results from Youth Interviews}

In the youth interviews, participants identified several reasons why they struggled with the prepost mode of deploying STEM-S surveys. Youth especially struggled because they lacked a clear frame of reference for assessing their current level of confidence or interest towards a topic. Participants mentioned that having a way to compare their interest to other youth or to themselves at another time would be helpful in answering self-reported measures. They 
described the self-reported assessments as "pointless" because they could not interpret the results and compare them with other similar results. Additionally, youth disliked repeating the exact same assessments necessary to the pre-post deployment mode. Consistent with previous research [6][7], the youth expressed that self-reported assessments detract from valuable hands-on activity time and greatly resemble school evaluations.

\section{Discussion and Lessons Learned}

The findings presented in the previous section show that using the retrospective mode when deploying self-reported surveys, such as S-STEM, can effectively measure perceived learning outcomes for youth. This mode of conducting surveys provides a better reference point than a pre-post mode for youth to reflect on changes in their abilities and attitudes. Additionally, conducting a retrospective survey once decreases the frequency of survey deployments which can improve youth's attitudes towards assessment in maker contexts. Following, we will share several lessons learned based on the findings presented above.

Using Retrospective Self-Reported Surveys to Assess Youth's Attitudes. Our findings show that adopting a retrospective mode when deploying self-reported surveys in a maker setting can better assess shifts in youth attitudes and interests. These results concord with previous research that indicates this mode of deployment effectively measures self-reported shifts in behavior change. It can also help alleviate incomplete data sets by reducing the number of times data needs to be collected from the same participants [18][19].

Conducting Meaningful Assessments. Our findings indicate a need to contextualize self-reported assessments for youth in informal learning, and specifically maker, settings. When completing these assessments, youth need support to reflect critically on shifts in their attitudes and performance through assessment designs that support self-evaluation and critical thinking.

Without a clear point of reference, youth struggle to identify whether shifts in their attitudes have occurred and understanding the relevance of these shifts for them going forward. These concerns primarily existed in self-reported measures (i.e., STEM-S surveys) and did not arise in relation to the AUT. These results align with previous research that showed the youth had more positive attitudes towards AUT since it requires participants to exercise their problem-solving and creativity skills rather than self-report to complete the assessment [6][7].

Participatory Approaches Towards Youth Assessment. While the idea of using a retrospective mode of deployment originated from DHF staff's observations of youth performances during pre-post assessments, asking representative youth about their feedback towards the assessment tools helped identify some causes of youth's negative attitudes towards assessment tools. We recommend including youth, especially youth with experience completing assessments, in the design and re-design of context-aware tools and procedures. This participatory approach can help avoid creating negative attitudes towards assessment and lead to innovations informed by youth perspectives.

\section{Limitations and Future Work}

In the current study, we focused on a relatively small number of participants over a short period of time. In the future, we plan to continue collecting retrospective STEM-S survey data, as well as, AUT data from DHF youth to track any longitudinal changes in the current results. 
Additionally, we will deploy these assessment tools at collaborating sites that are running similar maker learning program to validate the current results across sites and with larger number of participants. We are also planning to explore how to extend assessment tools for use by elementary age children in similar contexts.

In the current study, we conducted a small number of interviews with youth participants. In the future, we would like to use focus groups with a larger number of youths to collect input about youth perspectives on assessment tools and procedures in this context. Findings would inform the future creation of collaboratively designed tools for youth assessment.

\section{Conclusion}

Maker programs in afterschool settings can introduce youth to engineering, technology and design concepts and processes early on and engage them in hands-on collaborative learning experiences. As interest in these programs grows, researchers and practitioners must identify effective assessment tools and strategies to determine the impact of these programs on youth. We studied two assessment modes, a pre-post mode and a retrospective mode, at an organization that provides youth maker learning programs. Using two assessment tools, Alternative Uses Test (AUT) and Upper Elementary School and Middle/High School Student Attitudes toward STEM (S-STEM) Surveys, we found that the pre-post mode showed insignificant and sometimes negative changes in youth creativity and interest. Interviews with youth found that they considered self-reported measures meaningless and struggled identifying a frame of reference for self-assessment. Subsequent results from the S-STEM surveys deployed using a retrospective mode that asked youth about their interests before and after completing a program showed significant positive gains for both incoming and more experienced, member youth, at DHF. In light of these results, we recommend program staff consider deploying similar self-reported surveys using a retrospective mode.

\section{Acknowledgements}

This research supported by the National Science Foundation under Grant No. DRL-1723610 and Grant No. EEC-1623490. Any opinions, findings, and conclusions or recommendations expressed in this material are those of the authors and do not necessarily reflect the views of the National Science Foundation.

\section{References}

[1] \# S. L. Chu, R. Schlegel, F. Quek, A. Christy, and K. Chen, “'I Make, Therefore I Am': The Effects of Curriculum-Aligned Making on Children's Self-Identity," in Proc. of the 2017 CHI Conference on Human Factors in Computing Systems, 2017, pp. 109-120.

[2] \# L. Martin, "The Promise of the Maker Movement for Education," J. Pre-College Eng. Educ. Res., vol. 5, no. 1, Apr. 2015.

[3] \# P. Blikstein and D. Krannich, "The makers' movement and FabLabs in education: experiences, technologies, and research," in Proc. of the 12th international conference on interaction design and children, 2013, pp. 613-616.

[4] \# S. Jordan and M. Lande, "Might young makers be the engineers of the future?," in Proc. of the Frontiers in Education Conference (FIE), 2014 IEEE, 2014, pp. 1-4. 
[5] \# S. Papavlasopoulou, M. N. Giannakos, and L. Jaccheri, "Empirical studies on the Maker Movement, a promising approach to learning: A literature review," Entertain. Comput., vol. 18, pp. 57-78, 2017.

[6] \# F. Hamidi, S. Grimes, S. Grime, C. Wong, and A. Hurst. "Assessment tools for an afterschool youth maker program." in Proc. of the 7th Annual Conference on Creativity and Fabrication in Education, 2017, 1-4.

[7] \# F. Hamidi, W. Easley, S. Grimes, S. Grimes, and A. Hurst. "Youth Attitudes Towards Assessment Tools in After-school Informal Learning and Employment Training Programs", in Proc. of 2018 ASEE Annual Conference \& Exposition, 2018.

[8] \# M. Faber, A. Unfried, E. N. Wiebe, J. Corn, L. W. Townsend, and T. L. Collins. "Student attitudes toward STEM: The development of upper elementary school and middle/high school student surveys." in Proc. of the Proceedings of the 2013 ASEE Conference and Expo, 2013.

[9] \# M. A. Runco and S. Acar, "Divergent thinking as an indicator of creative potential," Creat. Res. J., vol. 24, no. 1, pp. 66-75, 2012.

[10] \# J. P. Guilford, "The structure of intellect.," Psychol. Bull., vol. 53, no. 4, p. 267, 1956.

[11] \# P. Blikstein, S. L. Martinez, and H. A. Pang, Meaningful Making: Projects and Inspirations for Fab Labs and Makerspaces. Constructing Modern Knowledge Press, 2016.

[12] \# Open Portfolio Project Team, S. Chang, L. Regalla, and G. Mohammadi, A Practical Guide to Open Portfolios. CreateSpace Independent Publishing Platform, 2016.

[13] \# N. O. Ornelas, G. Calderon, and P. Blikstein, "Makers in Residence Mexico: Creating the Conditions for Invention," in Proc. of the FabLearn Europe Conference, 2014.

[14] \# E. Hamner, T. Lauwers, D. Bernstein, I. R. Nourbakhsh, and C. F. DiSalvo, "Robot Diaries: Broadening Participation in the Computer Science Pipeline through Social Technical Exploration.," in AAAI spring symposium: using AI to motivate greater participation in computer science, 2008, pp. 38-43.

[15] \# Open Portfolio Project Team, S. Chang, L. Regalla, and G. Mohammadi, A Practical Guide to Open Portfolios. CreateSpace Independent Publishing Platform, 2016.

[16] \# K. Qiu, L. Buechley, E. Baafi, and W. Dubow, "A curriculum for teaching computer science through computational textiles," in Proc. of the International Conference on Interaction Design and Children, 2013, pp. 20-27.

[17] \# P. J. Allen, G. G. Noam, T. D., Little, E. Fukuda, B. K. Gorrall, \& B. A. Waggenspack. 2017. "Afterschool \& STEM system building evaluation 2016," The PEAR Institute:

Partnerships in Education and Resilience, Belmont, $M A$.

[18] \# J. Drennan and A. Hyde. "Controlling response shift bias: the use of the retrospective pretest design in the evaluation of a master's programme," Assessment \& Evaluation in Higher Education 33 (6), pp. 699-709, 2008.

[19] \# M. Raidl, S. Johnson, K. Gardiner, M. Denham, K. Spain, R. Lanting, C. Jayo, A., Liddil, and K. Barron, "Use retrospective surveys to obtain complete data sets and measure impact in extension programs, ” Journal of Extension, 42(2), 2004.

[20] \# "Mind Garden." [Online]. http://www.mindgarden.com/. [Accessed: 03-Feb-2018]. 